\title{
Erratum to: Earth Pole Motion Due to Nonstacionary Perturbations
}

\section{D. Akulenko ${ }^{a}$ and V. V. Perepelkin ${ }^{b, *}$}

${ }^{a}$ Ishlinsky Institute for Problems in Mechanics, Russian Academy of Sciences, Moscow, 119526 Russia

${ }^{b}$ Moscow Aviation Institute (National Research University), Moscow, 125993 Russia

*e-mail: vadimkin1@yandex.ru

Received May 20, 2020

DOI: $10.3103 / \mathrm{S} 0025654420010252$

The name of the second author should read V. V. Perepelkin.

The original article can be found online at https://doi.org/10.3103/S0025654419070112 